\title{
Multi-Criteria Decision-Making Methodology for Sustainable Creativity in Social Media
}

\author{
${ }^{1}$ Shilpi Sharma, ${ }^{2}$ Tanupriya Choudhury and ${ }^{3}$ Bhupesh Kumar Dewangan \\ ${ }^{1}$ Department of CSE, Amity School of Engineering and Technology (ASET), Amity University, \\ Uttar Pradesh, Noida, Pin- 201303, India \\ ${ }^{2}$ Informatics Cluster, School of Computer Science, University of Petroleum and Energy Studies (UPES), \\ Dehradun, Uttarakhanda, Pin- 248007, India \\ ${ }^{3}$ Department of Computer Science and Engineering, School of Engineering, \\ O.P. Jindal University, India
}

Article history

Received: 23-06-2021

Revised: 12-11-2021

Accepted: 15-11-2021

Corresponding Author:

Tanupriya Choudhury

Informatics Cluster, School of

Computer Science, University of

Petroleum and Energy Studies

(UPES), Dehradun, Uttarakhand,

Pin- 248007, INDIA.

Email: tanupriya@ddn.upes.ac.in tanupriya1986@gmail.com

\begin{abstract}
A major topic that every researcher is pursuing is sustainability in every aspect of knowledge and learning. In the 21 st century, the world is facing a challenge. Some of the well-known Multi-Criteria Decision-Making tools are Analytic Network Process (ANP), Analytical Hierarchy Process (AHP), TOPSIS, ELECTRE, Choice Based Conjoint Analysis (CBC) etc. This approach is used in various research domains. The purpose of this study is to evaluate and find result for the queries based on reviews like which measures correlated to the sustainable environmental features involved in the development of social media? Which measures is most commonly used? What type of MCDM methods suitable for variety of social media? Is any different evidence for methods used for sustainable social media selection? Our focus was on analyzing the methods of choice and the criteria for result evaluations. In the spatial analysis the decision making is the main element in geographic studies and skills related to the success towards the planning process. MCDM focuses to analyzing decision problems and estimating the substitute to take decision for the preferences, privations the competence, handle spatial data for analysis. Ranking of influential users is most frequently used criteria followed by privacy, seriousness about reading terms and conditions and accurate quality and quantity.
\end{abstract}

Keywords: MCDM, Selection Criteria, Social Media, Privacy, Awareness

\section{Introduction}

In recent times the entire landscape is changed drastically, with increased popularity and practice of social media for using it for market their business for anyone. Online users on different platforms namely Facebook and Twitter create large social media where a million users communicate and interact with each other in groups. Thus, social media competitiveness depends on few parameters like the effect of the service provider, the use of modern technologies, sharing information, high suppleness, extended visualization, emphasis on central strength, competent security algorithm and more recently increasing on sustainability (Lambert et al., 1998). The parameters mentioned above are interdependent, that illustrates poor supervision. Flouting the factors makes social media less competent and decreases the competitiveness of social media and its presence in the market.
Nowadays every individual is accessing one or the other online social platform to be in contact with their known social circle members. Social media encourages self- expression and socialization that interprets relationships within a community having coordination with an acquaintance, friendship, mutual support and cooperation (Pujol et al., 2002). In 2018, Facebook reported having 1.47 billion active users who spend an average of 1200 seconds daily on their website. The Facebook groups feature in particular, seem to have gathered more popularity than others by enabling discussions via the use of forums and threads, bringing together like-minded people (Park et al., 2009). Sustainability has defined its mode into "public awareness", which allows communication towards sustainability credentials. It promotes forward-thinking to many organizations. Social media platforms have provided countless benefits to the business. The internet and other 
technology provide vital opportunity for enterprises that demands their sustainability energy with clients and shareholders. Social media is a self-sustaining force that is generated by like-minded people who were passionate consumers, employees, investors and members of traditional media. And more importantly, they know that their collective voice can influence others.

Sustainability has newly addressed a group of accomplishments. The mentioned publications are related to significant partners of social media from influential users, third parties, etc. (Karvetski et al., 2011). Firstly, in distinct social media how influential users put significant emphasis on sustainability. Secondly, the sustainable problems with social media are not often involved in selection process (Bajec et al., 2015). Considering the statistics towards sustainable awareness that touches the influential users and popularity of social media sites, higher profit, marketing benefits, etc. (Gensler et al., 2013). Taking initiative in this area seems mandatory but depends on the willingness of not only the social media sited but also to the sustainability of influential users of social media. Henceforth, this is logical to consider other environmental rations for selection procedure of the service provider. It starts with the proper selection criteria and correct methods by which we select a sustainable social media.

In America, the internet has $73 \%$ diffusion where maximum users have a community in social media. Approximately fifty million people are known to have FB accounts with approximately 35 million distinct individuals (Bausch and Han, 2006). Persons who use the internet are teenagers who are more comfortable than average Americans (Madden and Fox, 2006). The internet and social media provide access to a large population including teenagers, middle-aged professionals and grown-ups (Mankoff et al., 2007).

This article aims towards preparing a framework related to the selection criteria and the methodologies for proper selection.

Which social media site is likely to be used by users? Are they all easy to use and well well-defined? Does it cover any specific area of sustainability related to environment? Is there any relevance among the frequencies of the usage in different countries (Lenhart et al., 2005).

What method is suited for the selection of social media? Which methods are most commonly used? Are the values and flaws be considered? Any variance in the methods used for sustainable social media selection? Does the selection of methods intervene by any third party or service providers (Beškovnik and Bajec, 2015).

\section{Related Work}

Social media networks are currently a part of several interdisciplinary needs where the whole virtual communication environment is achieved with different objectives (Krishen et al., 2016). Streamlining the social media networks under the area of marketing and management, the complete focus is drawn onto the betterment of the reputation of the company and its product or services, persuading active members to propagate the material of advertisement campaigns, deducing promotion costs and hale the quantity of product sold (Wang et al., 2016).

A plethora of users of social media pumps up the organizations directly to alter their advertisement campaigns by quickly adapting to the changing user's informational requirements (Ashley and Tuten, 2015).

In accordance to the interests of individuals and the needs to express one's individuality, social networks can be categorized as when they need visual experience through photos ("Pinterest", "Stumble Upon "); when they share videos and be in touch with other like-minded people; create blogs ("Tweet Peek", "Twitter"); extract information("Google ", "Yelp"); participate in discussion forums ("MS Skype") broadcasts videos (" Juntin"); maintain relations and express themselves (" Facebook", "Twitter", "Gplus") (Felix et al., 2017).

A study done for the Tour and Travels area showed that more than $80 \%$ of users of social media prefer other users' views to make purchasing choices. It has been concluded that $97 \%$ of respondents are affected by other member's thoughts and feedback while organizing a tour. Users tend to have more confidence in the opinion of other users who have previously used the product or a particular service, in comparison to company marketing. This influence of customers is called social influence that inspires other customer's inclinations by molding their attitudes and behaviors (Sheikhahmadi and Nematbakhsh, 2017).

There is multiple type of works in the literature of social media which correspond to influential user identification. Several models were presented where the algorithm used training and test data. The algorithm was first fed with various parameters and it was used to make predictions. A model is proposed where the sentiment analysis of text in social media is calculated by polarity and subjectivity (Barreto and Whitehair, 2017). Twitter was chosen as the platform for identifying the influential user by Weng who proposed Twitter Rank (Goyal et al., 2010; Pang et al., 2002) offered a weighted theory. Leader Rank technique that permitted users with more fans gets more scores. They prefer a standard random walk as compare to a biased random walk. Researchers identified the problem of finding a cluster of influential users but failed to recognize such users using minimum computing power (Turney, 2002).

The prerequisite to meet the issue of distinguishing potential influencers and rank the influencers is to understand the aspects of the social media environment by building algorithms, developing formulae to compute the influence probabilities. The problem contains the parameters 
like subjective or objective, tangible or intangible, qualitative or quantitative etc. out of these any two alternatives can be treated as MCDM problems. These MCDM methods are beneficial and suitable for explaining many issues related to influential users. The field of the MCDM technique is still new where more than $80+$ diverse methods exist and clusters are formed based on similarity. The classification methods adapted are Linear weighting models, Statistical approaches, Mathematical programming, Probabilistic methods, outranking methods and Artificial Intelligence (Weng et al., 2010)

MCDM problem always contains replacements where decision-makers must pick the best and matching objectives by the influential users and third parties of social media (Li et al., 2014). The requirement criteria for selection depend on performance cost, the ability of the provider, flexibility, the quality of performance etc. Further, the criteria are classified by grouping operational capability, service level, cost, the status of the provider and environmental capability.

The survey analysis report (Davies and Cranston, 2008) on various groups in social media like Facebook sketches that these platforms play a vital part in sending youth towards civic and political activities. Social media groups provide awareness for youth to actively participate in society, to socialize with others based on common interest.

The Fuzzy MCDM is used in multiple applications like performance evaluation of bankers, supplier selection, assessment of health-care, the performance of academicians and other selection processes. The decision making in such applications is effective. Thus F.M.C.D.M may prove to be useful to analyze all domains of any application which may be logical, theoretical, or numerical (Aruldoss et al., 2013).

The coordination is explicitly required between effective environmental decision making with technological, economic, ecological and socio-political factors. The majority of such qualities include various supplementary domains. An effective framework is designed to systematically organize the people, product and process for making a structured decision including the use of risk and cost-benefit analysis. The integration of heterogeneous information concerning human aspirations and technical applications demands a systematic and understandable framework for credible decision making (Kiker et al., 2005).

A novel integrated methodology was proposed that is based on the FMCDM framework for an effective sustainable supplier evaluation problem. Considering all aspects of the socio-economic environment a complex model was created with perfect information. Few selective decisions are often made under time pressure, limited capabilities or comparison is difficult. The two processes that are important for suppliers to maintain sustainability should be environmentally and socially responsible. The factors that can help suppliers to resolve sustainable issues are regular meeting, their performance criteria and social behavior (Büyüközkan and Çifçi, 2011).
A case study concerning the assessment procedure of interested parties should be socially acceptable. The pointer qualitative scale was applied to check participants who are against the installation, few are rigid to install a plant that is far from residential areas. Such criterion estimates the global social and economic effects based on job criteria (Cavallaro, 2005).

\section{Research Methodology}

The literature review was directed in three stages, first stage is to plan the review, second stage is to implement the reviews and third stage is to report the result (Tang and Yang, 2012).

Planning includes determination for review and considers the research target. Identifying the breaches in the current system, the selection of social media and the methods of MCDM that contribute to the selection process were discussed.

The review started with the precision of key words i.e. decision making procedures, assortment of third-party service providers or selection of influential users. Here, the determination of a time frame and search boundaries were taken into consideration. The collection of the article started with a review of those journals, conference papers and books related to multi-criteria decisions and in the field of social media, third-party service providers and influential users. Also, manual search from repository of research papers followed by each citation of background study was done. Around 100 publications in the field of MCDM and social media were analysed and critically evaluated (Zardari et al., 2015).

In this earlier defined criterion for selection of social media to generate discussions and narrow down the list to the significant features. The chosen measures were used "privacy", "confidentiality", "influence", "terms and conditions", "risk", "ease to use" and "open platform". A survey was carried out by 1205 users who filled an online questionnaire to understand the awareness of social media. Among this $37 \%$ were male and $63 \%$ were females. And the statistics of social media users are categorized on basis of age of the respondent, where majority percentage i.e., $62 \%$ of 748 (62\%) respondents fall between the age group of 20-40 years and $34 \%$ of 1205 that is 415 respondents fall between 12-19 years, 3\% of total respondent are between $35-40$ and only 7 (i.e., $1 \%$ ) respondents are 50 years + who use social media. The majority of the respondents $(72 \%)$ were academicians and $28 \%$ were professionals. The focus was to understand the influential user's attitudes toward social media and preferences. Academicians, Industry Experts and Technical Experts provided a vision on present and future inclinations on the usage of social media. Table 1 illustrates the items included with their levels. 
Table 1: Choice-based conjoint analysis on attributes and levels

\begin{tabular}{lll}
\hline Attribute & Level in No. & Remark \\
\hline Type of users & 4 & Student, Employees, Housewives, Entrepreneur \\
Privacy Disclosure Awareness & 4 & Private, Public \\
Security Issues & 4 & Permission, Private/Public Groups, Service Provider, Social Media \\
Types of Posts & 4 & Influential, Fun, Remove stress \\
\hline
\end{tabular}

\section{Methods of MCDM}

Fuzzy MCDM is applied to various applications to achieve the superlative solution and decision. In social media, the user behavioral changes are affected by other users called Social Influential Users. Various factors that influence the network of users are the distance, temporal effects and type of network. The standard network metrics are defined as follows.

\section{Degree}

The degree $\mathrm{k}$ of any node is no. of edges connected, where the degree of ' $i$ ' is the degree of node ' $i$ ':

$$
C_{i}^{D E G}=\operatorname{deg}(i)
$$

\section{Closeness}

The distance metric between all pairs of nodes. Shortest path distances to all other nodes:

$$
C_{i} C L O=e i T S 1
$$

where, $S$ is matrix of $(i, j)$ element of shortest path and 1 is the all one vector.

\section{Eigen vector Centrality}

It assigns a relative score to all nodes based on connections of high scoring nodes and low scoring nodes. Where $\lambda$ is a constant and A represents the adjacency matrix:

$$
x(i)=\frac{1}{x} \sum_{j=1}^{n} A_{i, j} x(j)
$$

Decision-making methodologies are separated from each other by using different calculation methods. The important algorithm namely the core process is defined by separating from other decision-making methods (Gupta et al., 2017).

\section{AHP}

AHP abbreviated for Analytic Hierarchy Process (Saaty, 2008). AHP proposes the complexities be broken down into similar sub-scope comparisons, assigning comparative ratings and analyzing the outcome to determine the best result (Zare et al., 2018). To do this, first, the problem needs to be defined and a best-suited structure needs to be determined using a decision hierarchy. The priorities are analyzed in parallel and resulted to determine the best fit. This now aids the decision-makers and the security professionals in addressing complex problems. In the past 40 years of its growth, AHP has built many applications. AHP has not only grown in Information system security but also business. Studies have included guiding information security investment decisions and evaluating antiviruses (Darko et al., 2019). Because of this, the comparative studies shown that the results of AHP-based preference measurement, not only analytical high accuracy but also accurate measurement for complex products (Mulye, 1998).

Let, $\mathrm{A}=\left(a_{i j}\right) \alpha$ is $n^{*} n$ judgment matrix. Firstly, the column vector is normalized in the judging matrix, then adds the normalized matrix in the rows. The result has to be normalized again to get the Eigenvector:

$$
w_{i}=\frac{1}{n} \sum_{j=1}^{n} \frac{a_{i j}}{\sum_{k=1}^{n} a_{k j}}(i=1,2, \ldots, n)
$$

\section{$C B C$}

From being a prompting methodology to the most popular consumer preference in the last three decades, Conjoint Analysis (CA) became popularly known as Choice-Based Conjoint (CBC) in the 90's. here the participants were requested to choose among given combinations instead of ranking or rating (Wiley et al., 2010). CBC is mainly common for realism in terms of ranking and rating for predicting the market shares or developing the pricing strategies (Mankoff et al., 2007). Presently CBC is widely used as consumers in real life and series of possible combinations are presented to the respondents. These scores determine the chosen levels and the comparative priorities for each factorization. Scaling is done to scale the score to an arbitrary additive constant within each element (Chatterjee and Chakraborty, 2012).

In each task $t=1, \ldots . T$, the $i$-th respondent chooses one of the $j$ profile shown. Then use a Logit model to estimate the probability Pij,t of this respondent choosing the alternative $j$ ' as:

$$
P_{j ; t}\left(X_{i t} \beta\right)=\frac{\exp \left(X_{i j, t} \beta_{i}\right)}{\sum_{j=1}^{n j} \exp \left(X_{i j, t} \beta_{i}\right)}
$$

where, $X_{i j}$ is the profile description of the $j$-th alternative in the $t$-th choice and $X$ represents a matrix of all profile descriptions in the task $t$ shown to the respondent $i$. 


\section{Topsis}

The algorithm for TOPSIS defines the distance from both the positive and the negative solutions to an ideal benchmark (Madić et al., 2015). In this methodology following steps are considered:

Step1: The normalized values are calculated by using the alternatives $\mathrm{m}$ and criteria $n$, thus the normalized values $\left(R_{i j}\right)$ is defined as:

$$
R_{i j}=\frac{A_{i j}}{\sqrt{\sum_{i=1}^{m} A_{i j}^{2}}} i \in[1, m], j \in[1, n]
$$

Step 2: Generate the normalized values by providing weights to the criteria $\left(V_{i j}\right)$ :

$$
V_{i j}=W_{j} * A_{i j}, i \in[1, m], j \in[1, n]
$$

Step 3: For every ideal alternative find the best performance $(\mathrm{s}+)$ and worst performance $(\mathrm{s}-)$ :

$$
\begin{aligned}
& S^{+}=\left\{v_{1 j}, v_{2 j}, v_{3 j}, \ldots, v_{m j},\right\}=\left\{\max v_{i j} \text { for } \forall_{j} \in n\right\} \\
& S^{-}=\left\{v_{1 j}, v_{2 j}, v_{3 j}, \ldots, v_{m j}\right\}=\left\{\min v_{i j} \text { for } \forall_{j} \in n\right\}
\end{aligned}
$$

Step 4: Place the value of Eq. 9 for all the criteria of every alternatives distance to the best alternatives $(\mathrm{Di}+=)$ and worst alternative (Di -):

$$
\begin{aligned}
& D_{i}^{+}=\sqrt{\sum_{i=1}^{n}\left(V_{i j}-S_{j}^{+}\right)^{2} \text { for } i=1,2, \ldots m} \\
& D_{i}^{-}=\sqrt{\sum_{i=1}^{n}\left(V_{i j}-S_{j}^{-}\right)^{2} \text { for } i=1,2, \ldots m}
\end{aligned}
$$

Step 5: Finally the positive ideal solution $\left(C_{i}\right)$ is calculated as:

$C_{i}=\frac{D_{i}^{-}}{D_{i}^{-}+D_{i}^{+}} i=1,2, \ldots$ mand $0 \leq C_{j} \leq 1$

Thus the biggest $\left(C_{i}\right)$ value chosen for the MDCM problem is by obtaining best selection through TOPSIS.

\section{Fuzzy TOPSIS Method}

To study this, first we need to know about fuzzy MCDM. Fuzzy MCDM categorizes values and relative weights as fuzzy numbers. These fuzzy numbers include a convex fuzzy set of real number that ranges between 0 and 1 examples of which can be triangular and trapezoidal fuzzy numbers (Sharma and Sodhi, 2015). Fuzzy TOPSIS introduces an added input for measuring direct and indirect interdependencies for the scenarios of interaction among the various elements. The analysis can enhance consideration approach that can provide different understandings and contributions to the literature, thus advancing research in this field. It also pact with fuzzy MCDM problems. Defuzzification is don't break down the fuzzy MCDM into a simple discrete crisp set. This provides an estimation for each alternative with all relative closeness. The Euclidian distance between any two fuzzy numbers can also be drawn out by an extension of this method. Accordingly, alpha level sets can be seen in fuzzy TOPSIS method as follows.

Normalize the fuzzy decision matrix:

$$
\ddot{x}=\left(\tilde{x}_{i j}\right) n \times m
$$

by,

$\tilde{r}_{i j}=\left(\frac{a_{i j}}{d_{j}^{*}}, \frac{b_{i j}}{d_{j}^{*}}, \frac{d_{i j}}{d_{j}^{*}}\right), i=1, \ldots \ldots . . n ; j \in \Omega_{b}$

$\tilde{r}_{i j}=\left(\frac{\overline{a_{J}}}{d_{i j}}, \frac{\overline{a_{J}}}{d_{i j}}, \frac{\overline{a_{J}}}{a_{i j}}\right), i=1, \ldots \ldots . . n ; j \in_{C}$

Where,

$$
\begin{aligned}
& d_{j}^{*}=\max _{i} d_{i j}, j \in \Omega_{b} \\
& \bar{a}_{j}=\min _{i} a_{i j}, j \in \Omega_{C}
\end{aligned}
$$

Determine the ideal solution and the negative ideal solution:

$$
\begin{aligned}
& A^{+}=\left\{x_{1}^{+}, \ldots x_{m}^{+}\right\}=\left\{\left(\max _{j} d_{i j} \mid j \in \Omega_{b}\right),\left(\min _{j} a_{i j} \mid j \in \Omega_{c}\right)\right\} \\
& A^{-}=\left\{x_{1}^{-}, \ldots x_{m}^{-}\right\}=\left\{\left(\min _{j} d_{i j} \mid j \in \Omega_{b}\right),\left(\max _{j} a_{i j} \mid j \in \Omega_{c}\right)\right\}
\end{aligned}
$$

Compute the fuzzy relative closeness of each alternative by solving the NLP models:

$$
\begin{gathered}
\left(R C_{i}\right)_{\alpha}^{L}=\operatorname{Min} \frac{\sqrt{\sum_{j=1}^{m}\left(w_{j}\left(r_{i j}\right)_{\alpha}^{L}\right)^{2}}}{\sqrt{\sum_{j=1}^{m}\left(w_{j}\left(r_{i j}\right)_{\alpha}^{L}\right)^{2}+\sqrt{\sum_{j=1}^{m}\left(w_{j}\left(r_{i j}\right)_{\alpha}^{L}-1\right)^{2}}}} \\
\operatorname{s.t}\left(w_{j}\right)_{\alpha}^{L} \leq w_{j} \leq\left(w_{j}\right)_{\alpha}^{U}, J=1, \ldots \ldots, m
\end{gathered}
$$

and,

$$
\left(R C_{i}\right)_{\alpha}^{U}=\operatorname{Max} \frac{\sqrt{\sum_{j=1}^{m}\left(w_{j}\left(r_{i j}\right)_{\alpha}^{U}\right)^{2}}}{\sqrt{\sum_{j=1}^{m}\left(w_{j}\left(r_{i j}\right)_{\alpha}^{U}\right)^{2}+\sqrt{\sum_{j=1}^{m}\left(w_{j}\left(r_{i j}\right)_{\alpha}^{U}-1\right)^{2}}}}
$$




$$
s . t\left(w_{j}\right)_{\alpha}^{L} \leq w_{j} \leq\left(w_{j}\right)_{\alpha}^{U}, J=1, \ldots \ldots, m
$$

or,

$$
\begin{gathered}
\left(R C_{i}\right)_{\alpha}^{L}=\operatorname{Min} \frac{\sqrt{\sum_{j=1}^{m}\left(w_{j}\left(\left(x_{i j}\right)_{\alpha}^{L}-x_{j}^{-}\right)\right)^{2}}}{\sqrt{\sum_{j=1}^{m}\left(w_{j}\left(x_{i j}\right)_{\alpha}^{L}-x_{j}^{-}\right)^{2}+\sqrt{\sum_{j=1}^{m}\left(w_{j}\left(x_{i j}\right)_{\alpha}^{L}-x_{j}^{*}\right)^{2}}}} \\
\operatorname{s.t}\left(w_{j}\right)_{\alpha}^{L} \leq w_{j} \leq\left(w_{j}\right)_{\alpha}^{U}, J=1, \ldots \ldots, m
\end{gathered}
$$

and,

$$
\begin{gathered}
\left(R C_{i}\right)_{\alpha}^{L}=\operatorname{Max} \frac{\sqrt{\sum_{j=1}^{m}\left(w_{j}\left(\left(x_{i j}\right)_{\alpha}^{L}-x_{j}^{-}\right)\right)^{2}}}{\sqrt{\sum_{j=1}^{m}\left(w_{j}\left(x_{i j}\right)_{\alpha}^{U}-x_{j}^{-}\right)^{2}+\sqrt{\sum_{j=1}^{m}\left(w_{j}\left(x_{i j}\right)_{\alpha}^{U}-x_{j}^{*}\right)^{2}}}} \\
\operatorname{s.t}\left(w_{j}\right)_{\alpha}^{L} \leq w_{j} \leq\left(w_{j}\right)_{\alpha}^{U}, J=1, \ldots \ldots, m
\end{gathered}
$$

Rank alternatives in terms of their defuzzified relative closeness.

\section{Results and Discussion}

Finally, five criteria have been chosen:

$\mathrm{C} 1=$ Security

$\mathrm{C} 2=$ Terms and conditions

$\mathrm{C} 3$ = Type of posts

$\mathrm{C} 4$ = Usage capacity

C5 = User interface

The decision-making part builds the pairwise association matrix of the comparison criteria is shown in Table 2. The judgment is acceptable because the Consistency Ratio (CR) is less than 0.1 or close.

\section{Analytical Hierarchy Process (AHP)}

The questionnaire was designed for comparing all the criteria based on pairing. Firstly, a set of instructions was floated among the experts to explain the hierarchical structure of comparisons. The proposed scale was on the 1-9 point. Also, relative preferences on a scale of $0-1$ were analyzed. Figure 1 and 2 shows the different criteria with relative weight.

The analysis is conducted to ensure that the questionnaire was properly designed and the size of the survey was within specific requirements.

Among large numeral of alternatives, the ten most ideal alternatives were chosen to deport sensitive analysis. The weights of each criterion simulate a gradual random deviation by minus $10 \%$ of the order of preferences. Figure 3 shows the analysis of the risk associated with information disclosure.

\section{Choice-Based Conjoint Analysis}

Figure 4 displays the attribute based on the Logit Method and the average usage values for each of the levels. The ideal points and attributes that are based on the survey, depict positive values.

When analyzing the most commonly used it appeared to be applied different methods that are most appropriate for influential users.

In order to rank the alternative criteria's, TOPSIS method is applied at the final step. AHP can be used as the input in TOPSIS method to calculate the global weights of each sub-criterion. Using TOPSIS technique the normalizing of the aggregate ratings matrix, from Eq. (10), (11). (15) and (16), we calculate the positive and negative ideal solutions and the closeness coefficient with ranking of the alternatives are shown both in Table 3 and graphically represented in Fig. 5 .

Social media like any other area have their characteristics like: Qualitative criteria and quantitative criteria, conflict criteria and subjective criteria. The result of this analysis is presented in Table 4 with two key features and firstly most appropriate method and secondly which method could satisfy the characteristic of social media.

Table 2: Analysis Decision matrix after AHP evaluation (pair-wise)

\begin{tabular}{llllll}
\hline & C1 & C2 & C3 & C4 & C5 \\
\hline C1 & 0.23 & 0.47 & 0.22 & 0.05 & 0.03 \\
C2 & 0.50 & 0.13 & 0.27 & 0.07 & 0.23 \\
C3 & 0.39 & 0.07 & 0.08 & 0.21 & 0.36 \\
C4 & 0.07 & 0.04 & 0.08 & 0.02 & 0.07 \\
C5 & 0.6 & 0.52 & 0.28 & 0.12 & 0.06 \\
\hline
\end{tabular}

Table 3: The ranking of alternatives and final evaluation

\begin{tabular}{lllll}
\hline & $\mathrm{D}^{*}$ & $\mathrm{D}^{-}$ & $\mathrm{Ci}$ & Rank \\
\hline $\mathrm{C} 1$ & 0.128 & 0 & 0 & 5 \\
$\mathrm{C} 2$ & 0.05 & 0.05 & 0.09 & 4 \\
$\mathrm{C} 3$ & 0.018 & 0.025 & 0.032 & 1 \\
$\mathrm{C} 4$ & 0.012 & 0.02 & 0.012 & 2 \\
$\mathrm{C} 5$ & 0.052 & 0.037 & 0.052 & 3 \\
\hline
\end{tabular}


Shilpi Sharma et al. / Journal of Computer Science 2021, 17 (11): 1128.1137 DOI: 10.3844/jessp.2021.1128.1137

Table 4: MCDM methods - Strengths and Weakness that are frequently used

\begin{tabular}{|c|c|c|c|c|c|c|c|}
\hline Criteria & Qualitative & & Qualitative & Subjective & Objective & Ease of Use & Availability of software \\
\hline \multirow[t]{7}{*}{ Linear weighted models } & TOPSIS & $*$ & $*$ & $*$ & & $*$ & $*$ \\
\hline & ANP & $*$ & $*$ & $*$ & & $*$ & $*$ \\
\hline & AHP & $*$ & $*$ & $*$ & & $*$ & $*$ \\
\hline & ISM & $*$ & & $*$ & & & \\
\hline & SMART & $*$ & $*$ & $*$ & $*$ & & \\
\hline & VIKOR & $*$ & $*$ & & & $*$ & $*$ \\
\hline & QFD & $*$ & $*$ & $*$ & & $*$ & $*$ \\
\hline \multirow[t]{2}{*}{ Method depend on cost } & $\mathrm{ABC}$ & & $*$ & & $*$ & & \\
\hline & $\mathrm{TCO}$ & & $*$ & & * & & \\
\hline \multirow[t]{4}{*}{ Artificial intelligence } & EXPERT SYSTEM & $*$ & & $*$ & & & \\
\hline & $\mathrm{CBR} / \mathrm{RBR}$ & $*$ & & $*$ & & & \\
\hline & ANN & $*$ & & $*$ & & & \\
\hline & DELPHI & $*$ & & & $*$ & & $*$ \\
\hline \multirow[t]{3}{*}{ Social media and networking } & AHP & $*$ & $*$ & & $*$ & $*$ & \\
\hline & TOPSIS & $*$ & $*$ & & & $*$ & $*$ \\
\hline & ELECTRE & & $*$ & & & $*$ & $*$ \\
\hline
\end{tabular}

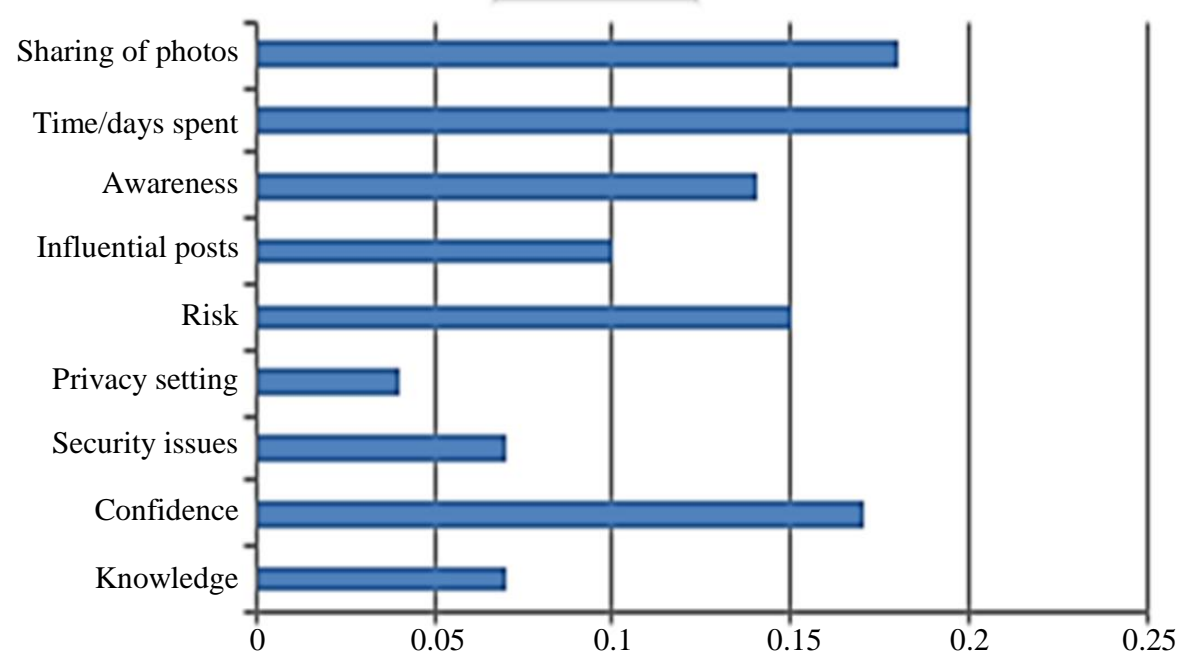

Fig. 1: Criteria of relative weight

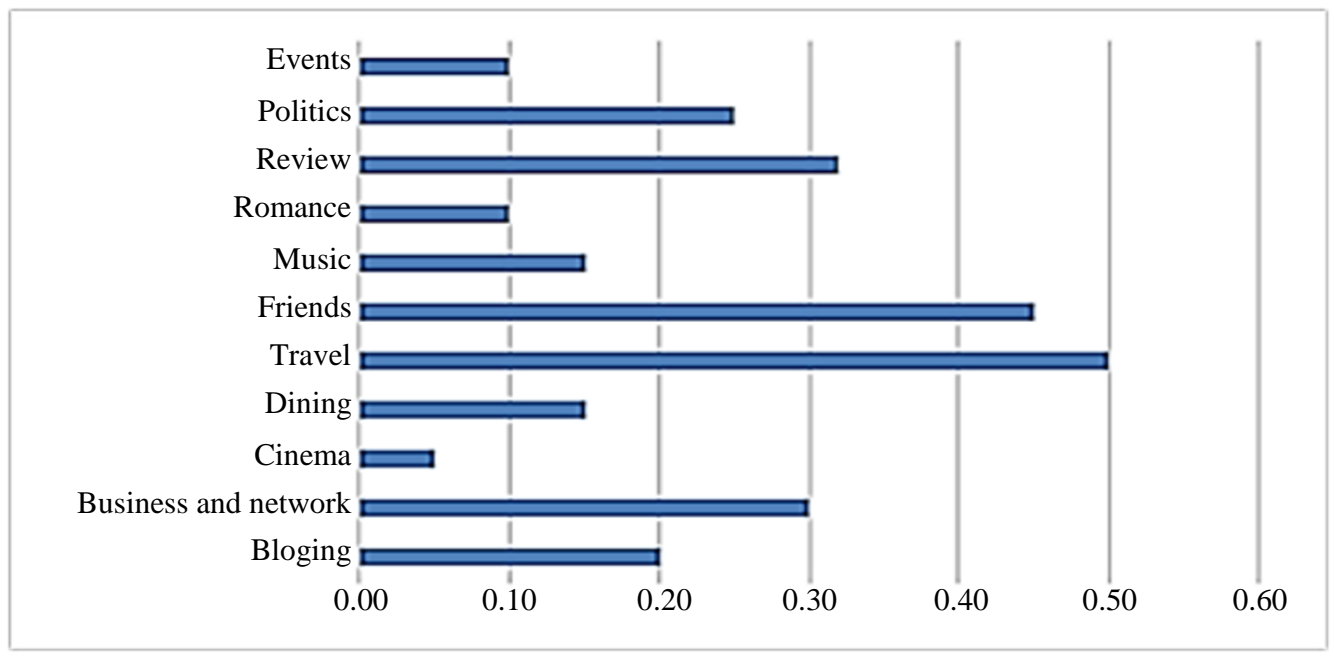

Fig. 2: Analysis of performance 


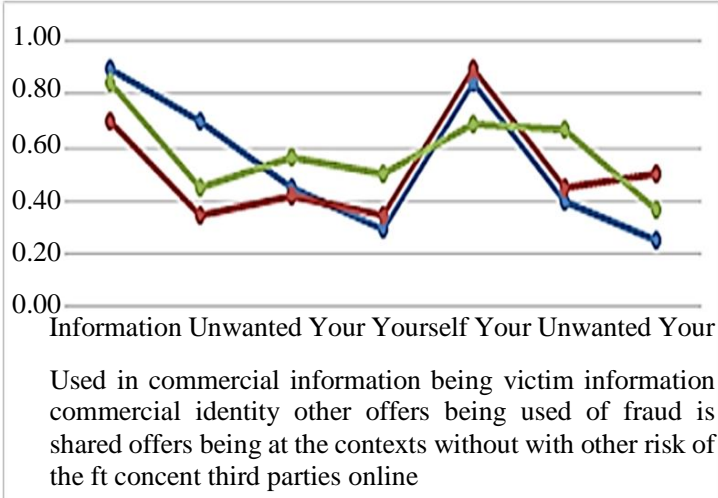

$\underset{\sim}{\infty}$ Series $1 \leadsto$ Series $2 \approx$ Series 3

Fig. 3: Sensitivity analysis of risk criteria

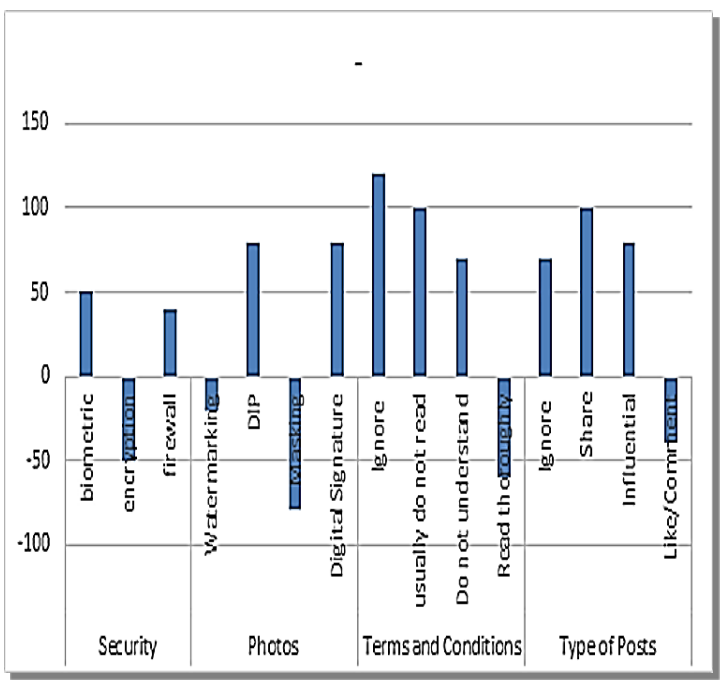

Fig. 4: Combinational attributes and levels

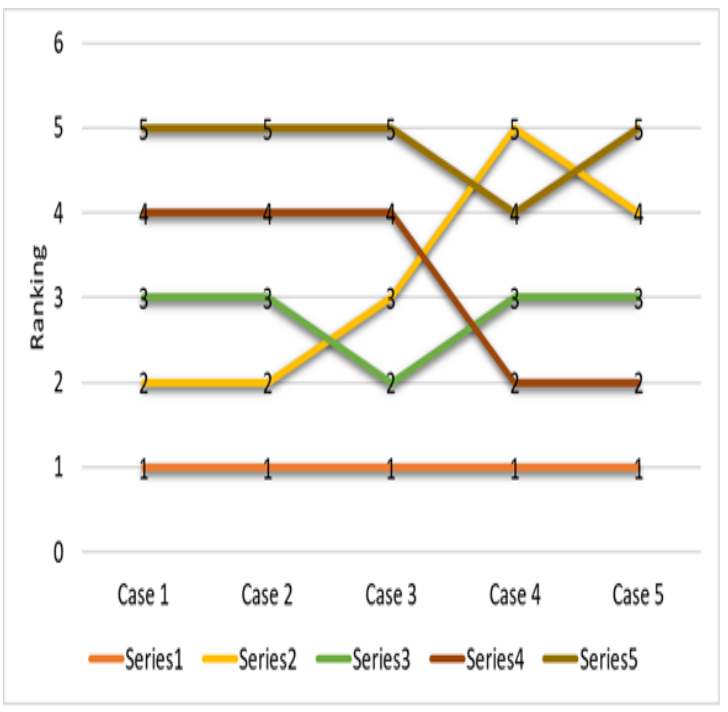

Fig. 5: Analysis of ranking criteria

\section{Conclusion}

A method that influences individual performance among millions of users who frequently visited social media. Regular reminders and suggestions related to changes or modifications are likely to increase by frequent viewing. Our proposed approach also influences information about respondents of social media. Planning to implement existing knowledge about community groups to design an effective model for encouraging users of social media. The preference ranking methods can be efficiently applied to decisionmaking problems with any number of alternatives involving qualitative, quantitative and gravy criteria. We used the respondents' subjective evaluations regarding their ability and willingness for comparing the practical applicability of CBC and AHP. The major concern in the study is the cost incurred for survey that rises with interview span and undesired withdrawal is undesirable of the survey. Surprisingly, it is observed that $\mathrm{CBC}$ is not rated to be more accurate. One reason for overloading can be the choice of tasks that are too complex. The Internet has dramatically revolutionized many different fields that have fabricated the way for many technological evolutions. Internet is a platform where every individual visit social media regularly. Social media plays a vital role in supporting influencers, the business market and the personality development of an individual. This can be appreciated in the existing environmental sustainability information on social media that focuses on the environment. Hence it would be possible to target the major population and provide information more frequently referred and adapted by users. Future scope of this research by applying CBC and AHP successively a valuable system is substantiated on different techniques. Considering the predictive accuracy AHP seems to be at least on par with CBC. Surprisingly the majority of today's market research institutions use $\mathrm{CBC}$ to analysis, trends and forecasts. Also, the most important advantage of AHP is the limitation of consistency. Thus, the dynamic properties of social media need to be included during the calculation of centrality measures and compare the experimental performance with benchmark results. Social Media can help researchers to understand that the adopted research has grown sustainable and the collaboration of interdisciplinary teams is across the geography.

\section{Author's Contributions}

Shilpi Sharma: Participated in all experiments, coordinated the data-analysis and contributed to the writing of the manuscript.

Tanupriya Choudhury: Guided the whole 
manuscript, completed the literature survey and completed the methods of MCDM.

Bhupesh Kumar Dewangan: Formulated the review responses, designed the figures with high resolution tool and formulated the results.

\section{Ethics}

This article is original and contains unpublished material. The corresponding author confirms that all of the other authors have read and approved the manuscript and no ethical issues involved.

\section{References}

Aruldoss, M., Lakshmi, T. M., \& Venkatesan, V. P. (2013). A survey on multi criteria decision making methods and its applications. American Journal of Information Systems, 1(1), 31-43.

http://citeseerx.ist.psu.edu/viewdoc/download?doi=1 0.1.1.953.3032\&rep=rep1\&type $=$ pdf

Ashley, C., \& Tuten, T. (2015). Creative strategies in social media marketing: An exploratory study of branded social content and consumer engagement. Psychology and Marketing, 32(1), 15-27. doi.org/10.1002/mar.20761

Bajec, P., Tuljak-Suban, D., \& Krmac, E. (2015). Do ISO standards favour logistics provider efficiency, competitiveness and sustainability? A Slovenian perspective. The International Journal of Logistics Management. doi.org/10.1108/IJLM-01-2013-0006

Barreto, J. E., \& Whitehair, C. L. (2017). Social media and web presence for patients and professionals: Evolving trends and implications for practice. PM\&R, 9(5), S98-S105. doi.org/10.1016/j.pmrj.2017.02.012

Bausch, S., \& Han, L. (2006). Social networking sites grow 47 percent, year over year, reaching 45 percent of web users. Retrieved January, 7, 2008.

Beškovnik, B., \& Bajec, P. (2015). Application of environmental and social sustainable measures by port of koper: The basis for the regional approach. Problemy Ekorozwoju-Problems Of Sustainable Development, 10(1), 99-106.

https://papers.ssrn.com/sol3/papers.cfm?abstract_id $=2556857$

Büyüközkan, G., \& Çifçi, G. (2011). A novel fuzzy multicriteria decision framework for sustainable supplier selection with incomplete information. Computers in industry, 62(2), 164-174.

doi.org/10.1016/j.compind.2010.10.009

Cavallaro, F. (2005). An integrated multi-criteria system to assess sustainable energy options: An application of the PROMETHEE method. doi.org/10.2139/ssrn.666741
Chatterjee, P., \& Chakraborty, S. (2012). Material selection using preferential ranking methods. Materials \& Design, 35, 384-393. doi.org/10.1016/j.matdes.2011.09.027

Darko, A., Chan, A. P. C., Ameyaw, E. E., Owusu, E. K., Pärn, E., \& Edwards, D. J. (2019). Review of application of analytic hierarchy process (AHP) in construction. International journal of construction management, 19(5), 436-452. doi.org/10.1080/15623599.2018.1452098

Davies, T., \& Cranston, P. (2008). Youth work and social networking. Retrieved October, 1, 2017. doi.org/10.1016/j.physa.2014.02.041

Felix, R., Rauschnabel, P. A., \& Hinsch, C. (2017). Elements of strategic social media marketing: A holistic framework. Journal of Business Research, 70, 118-126. doi.org/10.1016/j.jbusres.2016.05.001

Gensler, S., Völckner, F., Liu-Thompkins, Y., \& Wiertz, C. (2013). Managing brands in the social media environment. Journal of interactive marketing, 27(4), 242-256. doi.org/10.1016/j.intmar.2013.09.004

Goyal, A., Bonchi, F., \& Lakshmanan, L. V. (2010, February). Learning influence probabilities in social networks. In Proceedings of the third ACM international conference on Web search and data mining (pp. 241-250). doi.org/10.1145/1718487.1718518

Gupta, A., Thakur, H. K., Gupta, T., \& Yadav, S. (2017). Regular pattern mining (with jitter) on weighteddirected dynamic graphs. Journal of Engineering Science and Technology, 12(2), 349-364.

Karvetski, C. W., Lambert, J. H., \& Linkov, I. (2011). Scenario and multiple criteria decision analysis for energy and environmental security of military and industrial installations. Integrated environmental assessment and management, 7(2), 228-236. doi.org/10.1002/ieam.137

Kiker, G. A., Bridges, T. S., Varghese, A., Seager, T. P., \& Linkov, I. (2005). Application of multicriteria decision analysis in environmental decision making. Integrated Environmental Assessment and Management: An International Journal, 1(2), 95-108. doi.org/10.1897/IEAM_2004a-015.1

Krishen, A. S., Berezan, O., Agarwal, S., \& Kachroo, P. (2016). The generation of virtual needs: Recipes for satisfaction in social media networking. Journal of Business Research, 69(11), 5248-5254. doi.org/10.1016/j.jbusres.2016.04.120

Lambert, D. M., Cooper, M. C., \& Pagh, J. D. (1998). Supply chain management: Implementation issues and research opportunities. The international journal of logistics management, 9(2), 1-20. doi.org/10.1108/09574099610805485 
Lenhart, A., Madden, M., Hitlin, P., Lenhart, A. E., \& Madden, M. (2005). Teens and technology: Youth are leading the transition to a fully wired and mobile nation.

Li, Q., Zhou, T., Lü, L., \& Chen, D. (2014). Identifying influential spreaders by weighted Leader Rank. Physica A: Statistical Mechanics and its Applications, 404, 47-55. doi.org/10.1016/j.physa.2014.02.041

Madden, M., \& Fox, S. (2006). Riding the waves of "Web 2.0". Pew internet and American life project, 5. http://clearwww.cobw.com/Ethics/ethics_Web_2.pdf

Madić, M., Radovanović, M. I. R. O. S. L. A. V., \& Petković, D. U. Š. A. N. (2015). Non-conventional machining processes selection using multi-objective optimization on the basis of ratio analysis method. Journal of Engineering Science and Technology, 10(11), 1441-1452.

http://jestec.taylors.edu.my/Vol\%2010\%20Issue \%2 011\%20November\%202015/Volume\%20(10)\%20Is sue\%20(11)\%201441-1452.pdf

Mankoff, J., Matthews, D., Fussell, S. R., \& Johnson, M. (2007, January). Leveraging social networks to motivate individuals to reduce their ecological footprints. In 2007 40th Annual Hawaii International Conference on System Sciences (HICSS'07) (pp. 87-87). IEEE. doi.org/10.1109/HICSS.2007.325

Mulye, R. (1998). An empirical comparison of three variants of the AHP and two variants of conjoint analysis. Journal of Behavioral Decision Making, 11(4), 263-280. doi.org/10.1002/(SICI)10990771(1998120)11:4<263::AID-BDM301>3.0.CO;2-T

Pang, B., Lee, L., \& Vaithyanathan, S. (2002, July). Thumbs up?: Sentiment classification using machine learning techniques. In Proceedings of the ACL-02 conference on Empirical methods in natural language processing-Volume 10 (pp. 79-86). Association for Computational Linguistics. doi.org/10.3115/1118693.1118704

Park, N., Kee, K. F., \& Valenzuela, S. (2009). Being immersed in social networking environment: Facebook groups, uses and gratifications and social outcomes. Cyberpsychology \& behavior, 12(6), 729-733. doi.org/10.1089/cpb.2009.0003

Pujol, J. M., Sangüesa, R., \& Delgado, J. (2002, July). Extracting reputation in multi agent systems by means of social network topology. In Proceedings of the first international joint conference on Autonomous agents and multiagent systems: Part 1 (pp. 467-474). doi.org/10.1145/544741.544853
Saaty, T. L. (2008). Decision making with the analytic hierarchy process. International journal of services sciences, 1(1), 83-98. doi.org/10.1504/IJSSCI.2008.017590

Sharma, S., \& Sodhi, J. S. (2015). Social network analysis $\&$ information disclosure: A case study. International Journal of Computer and Information Engineering, 9(2), 567-575. https://publications.waset.org/10001376/socialnetwork-analysis-information-disclosure-a-case-study

Sheikhahmadi, A., \& Nematbakhsh, M. A. (2017). Identification of multi-spreader users in social networks for viral marketing. Journal of Information Science, 43(3), 412-423. doi.org/10.1177/0165551516644171

Tang, X., \& Yang, C. C. (2012). Ranking user influence in healthcare social media. ACM Transactions on Intelligent Systems and Technology (TIST), 3(4), 1-21. doi.org/10.1145/2337542.2337558

Turney, P. D. (2002, July). Thumbs up or thumbs down?: Semantic orientation applied to unsupervised classification of reviews. In Proceedings of the 40th annual meeting on association for computational linguistics (pp. 417-424). Association for Computational Linguistics. doi.org/10.3115/1073083.1073153

Wang, C., Guan, X., Qin, T., \& Yang, T. (2016). Modeling heterogeneous and correlated human dynamics of online activities with double Pareto distributions. Information Sciences, 330, 186-198. doi.org/10.1016/j.ins.2015.09.016

Weng, J., Lim, E. P., Jiang, J., \& He, Q. (2010, February). Twitterrank: Finding topic-sensitive influential twitterers. In Proceedings of the third ACM international conference on Web search and data mining (pp. 261-270). doi.org/10.1145/1718487.1718520

Wiley, J. B., Raghavarao, D., \& Chitturi, P. (2010). Choice-based conjoint analysis: Models and designs. doi.org/10.1201/9781420099973

Zardari, N. H., Ahmed, K., Shirazi, S. M., \& Yusop, Z. B. (2015). Weighting methods and their effects on multi-criteria decision making model outcomes in water resources management. Springer. doi.org/10.1007/978-3-319-12586-2

Zare, H., Olsen, P., Zare, M. J., \& Azadi, M. (2018). Operating System Security Management and Ease of Implementation (Passwords, Firewalls and Antivirus). In Information Technology-New Generations (pp. 749-755). Springer, Cham. doi.org/10.1007/978-3-319-77028-4_98 